\title{
Integrating small island sustainability
}

\author{
R. Moore \\ Anglia Ruskin University, Cambridge and Chelmsford, UK
}

\begin{abstract}
This paper identifies and considers the initial and ongoing sustainability outcomes of a small island tourism development following assessments by an independent international third party certification organisation's auditor using process based framework tools. A major aim of several parties involved in the associated 'in time' research was to ascertain specific environmental, social and economic measures implemented by a resort developer. These measures seen as being in response to increasing emblematic relevance, exacting government driven policies and broader community aspirations are crucial in delivering project sustainability. An objective of the broader case study research program has involved the engendering of links between theory and practical implementation of sustainable development principles with the reality of development. Another and equally pragmatic consideration was to review the use of process tools by those engaged in the planning, design, construction and eventual operation of the resort so as to determine the propensity needed in using performance framework models targeted at achieving sustainable development. Keywords: planning, design, management, operation, indicators, sustainability assessment.
\end{abstract}

\section{Introduction}

With an estimated 940 million international travellers leaving their home shores in 2010 and a predicted 3.3\% year on year growth until 2020 [1] travel and tourism is possibly the largest and fastest growing industry in modern economic terms. The approximate $\$ 2.4$ billion earned every day represents a capture of some $10 \%$ of the global economy [2] a figure likely to rise if the predicted growth takes place. Crucially these figures do not include domestic tourists who are even more numerous [3]. Of importance is a common feature found in the analysis of them and other supporting data, which is that many developing 
nations are and have been using travel and tourism for some time as a means to achieve socio-economic development [4-6]. When the stimulus links to the equally significant development and construction industry, the potential for ecological damage is immense. This has led to extensive pressure on these industries to ensure elimination or mitigation of the negative environmental impacts linked to tourism [7] and facility development [8].

Whilst environmental issues and concerns are always a central consideration linked to the preceding issues sustainable development also features permanently in the continuing debate. Intrinsically linked cultural, social and economic factors will attach to any discourse involving sustainability and associated ongoing and meaningful ecological performance outcomes. Also added to these should be the growing concerns regarding the possible though often ignored impacts of climate change [9]. Crucially long-standing matters and other newer issues must direct and influence consideration of the possible outcomes of small island coastal resort development [10-14].

Accordingly, connecting development with the principles of sustainability must be a major prerequisite in contemporary tourism provision [15] and physical infrastructure delivery [16]. In the reviewed case study, this expansive view is of crucial interest not least due to the coral islands unique nature and location and the client/developer and managing operator's goals and objectives. These interestingly predated the high profile ex-president of the Maldives [17] call for the Tourism Industry to ensure environmental and cultural sustainability.

Both reflected common messages which whilst recognizing the fact that for many small island states tourism is an important economic component this does not distract from the challenges associated with achieving sustainable development and improved quality of life. The complementing appeals reflected a long held and prevailing premise that even the slightest negative change in the delicate environment of specific island locations and nations could prove disastrous for all the parties involved [9, 18]. They along with others [19, 20] also demand protection, preservation and revitalization of the important though often, intangible cultural heritage and in particularly local practices and spaces.

Significantly, the general response by both government and industry at all levels has been mixed and somewhat deficient in pragmatic solutions. One cause may be the noted pluralism amongst the political-economic elite and a nonproductive familiarity between voters and politicians [21]. A further and immediate issue is the devolving of responsibilities to local authorities [22]. Many lack sufficient experience or the resources to ensure the appropriate controls needed for tourism developments. These crucial factors recognized some time ago are needed for appropriate planning, efficient development implementation and effective organizational structures for the on-going management of tourism and associated infrastructures [23, 24]. Of equal importance is the continuing lack of certainty regarding practical meanings for sustainability and sustainable development [25-27]. This lack of agreement ensures that uncertainty has always and continues to exist regarding what indicators to use $[12,28]$. Of equal importance when linked to this lack of certainty regards how to measure actual performance and outcomes [29]. 
Unfortunately, all the aforementioned areas are still attracting on-going debate leading to considerable confusion for those involved in actual development particularly as some now challenge the validity of sustainable development itself [30].

Conversely, despite this ensuing ambiguity there are examples of progressive developers challenging the delivery norms of tourism infrastructure. These best practice developments could assist in helping the aforementioned authorities for example overcome potential problems linked to their own considerable shortcomings [31]. Further, a growing number of companies are becoming fully aware that recognizing responsible environmental, cultural and social practices can translate into benefits for business, the environment and local and national community. The innovative solutions often utilised by them are known to provide important efficiencies, cost savings and reputation benefits through variety and reliability of supply in terms of improvement in production and quality control [32]. These outcomes will ensure long-term appeal and future success of a destination which makes sound commercial sense [33, 34].

In a major shift toward transparency, a prerequisite of sustainability some have opened their development planning, design and management processes to the scrutiny of internationally recognized assessment and certification standards (Moore Ed., [35]). This clearly indicates a willingness to reduce if not mitigate entirely the impacts of development. This is an essential response if such developments are not to become 'unregulated, formless or haphazard, inefficient and likely to lead directly to a range of negative economic, social and environmental impacts' [3, p.125].

\section{Research methodology}

The small coral island boutique resort described in this paper is one of a significant number of case studies where the outcomes of third party assessment are important for future attempts to undertake sustainable development in sensitive island locations [35]. This is because the associated certification process used on the case studies utilises key performance areas reflecting recognised pillars of sustainable development. The indicators and measures employed also find support from an exhaustive research approach and a major data base respectively [36, 37].

Quantitative and qualitative data is collected using benchmarking indicators determined as appropriate for assessing whether a resort is being planned, designed, constructed and managed in an ecologically sensitive manner. These indicators reflect Agenda 21 principles and translate into a range of goals that include the protection and conservation of ecosystems, a reduction of local impacts by a reduction in resource use and an the improvement of the local community's quality of life by equitable social and economic initiatives. The indicators and measures cover master planning and site utilization, energy efficiency, water conservation, wastewater and solid waste management, chemical use, social and economic commitment. Interrogation of the collected 
data is by using spreadsheets created from the use of assessment principles to indicator process models that address input, process and output factors [38].

The spread sheet output when matched to benchmarks enables comparisons with similar processes. The best practice outcome measures are a result of a database created from 10 years of recording operational performance. This extensive source and an increasing planning and design input from other case studies undertaken during a major research program provides an unrivalled rigor in resort development. The information gathered aids not only development and pre construction decision making but also determines on-going operational ecological performance outcomes of the resort in environmental, cultural, social and economic terms. There are recognised research limitations which do have implications. As noted the case study is one of a number of similar investigations into the planning and design, construction and operational management processes of a resort development. The analysis of these phases provides insights into the inception, evolution, construction and eventually management of travel and tourism infrastructure. The large number of case studies serves as a broad evidentiary base to compare the outcomes noted later [35].

The use of multiple case studies generates a cross case analysis which is both descriptive and covers explanatory topics [39]. This option recognizes that whilst each of the developments has their own context and perspective, the large number accommodates and overcomes the uniqueness and artificial conditions surrounding case studies outcome concerns regarding case study research [40]. In doing so, they are able to provide a means to access highly pertinent information and understanding of real life phenomenon. From the many results recorded, constructive observations along with viable implementation processes can be better formulated. The originality and value of the research recorded in this paper is the unique analysis of the correlations between desired development outcomes through increased cooperation, and actual real time process behaviour in terms of planning, design, construction and operational procedures. It also provides some early indication of continuing performance targets outcomes by linking seamlessly with the next phase of the total development process through post operational evaluations.

\section{The case study: a small island development}

\subsection{Primary vision and objectives}

The relevance of this case study is due in part to the primary objective of the Owner/Developer and the managing operator seeking to ensure that all planning, design and construction activities reflect ecologically sensitive methods [41]. Whilst partly in response to the strict selection criteria of the national approving authority, the organizations approaches reflected their own visions and supporting mission statement along with the use of an independent certification program. A linked aim of all involved was to ensure that the operation of the resort would achieve on-going ecological performance outcomes in environmental, social and cultural and economic terms. With the preceding 
goals, aims and objectives in mind the case study development has been subject to the assessment processes of a newly developed Building Planning and Design Standard [42]. This standard created for an international accreditation body offers a range of indicators, measures, guidelines and tools, employed to assist developers through the planning, design and construction phases along with the eventual operational management of a project when responding to sustainability agendas in practice.

The process based framework specifically encompasses the planning and building of tourism projects and associated facilities. The tool supports developers responding to ecological demands on tourism infrastructure development and measurement in terms of impacts and eventual performance outcomes. Significantly with this engagement and the ensuing data, critical planning and design decisions taken have some certainty of success [38].

The tool also provides a means by which developers and other stakeholders involved in projects reflecting sustainability drivers can achieve recognition and reward when achieving industry best practice. This is because a central dimension of the tool is to offer positive outcomes such as social and economic equity, reductions in pre planning timescales and greater certainty in actual performance delivery. This concurs with the perceived as appropriate whole systems approach [43] needed when seeking solutions to multiple problems brought on by the large number of interconnections that exists within a complex process based program of considerable sub-systems [44]. All features commonly found on projects pursuing a sustainable development agenda.

\subsection{Development background}

The assessed resort is on a small isolated and uninhabited coral island located in the central lagoon of the Gaafu Alifu Atoll Maldives. Ovular in shape the island's land area is approximately 7.75 hectares. The island is some $405 \mathrm{~km}$ south of the Maldives main international airport at Male. The nearest regional airport is $52 \mathrm{~km}$ with transfers take approximately 60 minutes by boat. Virtually on the equator, the island has an equatorial day and night cycle climate of no seasons with unpredictable tropical showers. Two regional monsoons take place between May and October and January to March. The island has a hot tropical climate with a temperature range of maximum $32^{\circ} \mathrm{C}$ and minimum $23^{\circ} \mathrm{C}$. Humidity is normally high though the surrounding sea provides a buffer through cooling sea breezes.

The island and the existing vegetation are relatively sheltered from oceanographic conditions and various wave forces. Of particular importance are the stands of Sea Trumpet and Sea Hearse that have ecological and cultural significance. There is abundant fish life in the lagoon and good coral cover. The \$(Aus)40 million medium sized resort offers 14 Aqua Villas and 36 Island Villas of which 20 have individual small pools. Of the two restaurants, opened one specializes in Maldives cuisine. The leisure concierge service provides access to all island activities and excursions most with a strong accent on cultural experiences. The developer and managers of the constructed and operational project are experienced companies that own and operate a number of resorts in the Asia Pacific region. 


\subsection{Primary outcome}

The utilised Building Planning and Design Standard (BPDS) applies sector benchmarking indicators (SBIs) and measures for building planning, design and construction management to assess the island resort. Having satisfied all the criteria and requirements of BPDS, the development achieved certification following an accredited Third-Party Auditor review of its processes and supporting documentation. The accreditation recognized that the development represents industry best practice.

The following albeit limited overview and comments reflect the outcomes of the assessment, which sought to determine achievement of the principal objectives of the standard to facilitate environmentally sustainable design and construction management of individual buildings and associated infrastructure.

\section{Overviews of KPAs, indicators and measures}

\subsection{Sustainable design and construction management policy}

In general the planning and design documentation showed that a sustainability approach, which prioritized cultural integrity and environmental protection, was very apparent. Carefully integration of villas and public facilities within the existing natural environment of the site ensured that they fitted in as unassumingly as possible to preserve the natural environmentt of the destination.

However an initial project appraisal including an operator interview regarding broad sustainability delivery objectives indicated the probability that possible ecological outcomes were under threat. Critically (on advice from the Assessor) increased involvement of a dedicated local environmental sustainable design consultant and several other international consultants from Norway, Thailand and Singapore remedied the situation by strengthening and integrating the design and management team more fully.

When reviewing the project due consideration was given to the issues of location and actual resources in the Maldivian Construction Industry. The location's scale and the difficult geographical access ensure a demanding market within in which to operate in respect of the local skills base, equipment and material sourcing. Despite these constraints encouragement in the selection of local contractors and subcontractors with sufficient experience to implement 'green' design including sustainable construction in subsequent contractual agreements was noted. Subsequent evidence submitted during the construction phase showed that an experienced local contractor was employed and good site management practices were eventually implemented.

\subsection{Siting}

Following an extensive and comprehensive Environmental Impact Assessment (EIA) a statutory requirement in the Maldives, the revised siting of public and service buildings reduced possible negative impacts and helped in the creation of positive effects on the natural environment. The location and design changes 
recommended in the EIA created a better use of the islands amenities particularly added value views and reductions in building area land coverage. Further, in responding to recommendations, revised designs for villas and resort facilities included larger open areas and less mechanical intervention.

\subsection{Site management and air quality protection and noise control}

Photographic evidence shows that by utilization of the EIA, reactive management actions and instructions reduced the environmental impact of building activities on site. Similar recorded evidence exists for the reduction of air and noise pollution from construction processes.

\subsection{Energy efficiency, conservation and consumption}

The use of a 'whole of systems' view for designing systems for reducing energy consumption at the resort formed part of the resorts reduced energy consumption vision and reflected in the actual building design documents provided. A key focus at the design stage is to ensure that adequate planning was undertaken and related decisions taken to control and reduce energy consumption. Details outlining overall energy consumption during construction of the resorts buildings and infrastructure reflected a desire to reduce energy usage during actual construction.

\subsection{Potable water usage and consumption}

The overall efficiency of potable water usage, promoting reductions without compromising the long-term operation of the resort, is part of the development's vision. Minimal consumption of potable water for construction activities is a primary target and reflected in the building and infrastructure design and construction practice recommendations.

\subsection{Solid waste production}

Reductions recorded in solid waste generated and disposed of by the resort achieved through implementation of a comprehensive on-site 'Waste Management Plan', which includes recycling and monitoring. Reduction in solid waste generated during the construction achieved through the design and process management. This area had proved problematic but management responses during the construction phase were positive though somewhat limited particularly regarding storage prior to disposal.

\subsection{Resource conservation}

The EIA and design responses helped reduce consumption of natural resources and impacts on the island's ecosystem and biodiversity. Reduction in the consumption of natural resources and impacts on ecosystem biodiversity achieved through firstly the nature of the development and secondly by agreements with the local community. 


\subsection{Waste water management}

Mitigation design measures for the waste water system provides onsite treatment using non-chemical means and planned disposal arrangements noted in the EIA and by the ESD Consultant. Reductions through design of building wet systems, processes, and a strategy for use of wastewater for recycling purposes.

\subsection{Social, cultural and economic commitment}

Positive, productive and sustainable contributions to the local community were planned and already evident firstly in the eventual operations staffing requirements and secondly in the short-term construction employment opportunities.

\section{Influences and benefits}

The standard would normally make no comment on client developer decisions to secure or promote particular development land however, the manner undertaken to secure this Island is however of interest. The transparent procedure outlined by the Maldives Government documentation and followed to initially place a bid and secure the right to develop the island has influenced project outcomes.

The strict tendering criteria clearly indicated that bidding to develop the island was an expensive business proposition with no guarantee of success in the tender process. Further initial briefing of professionals such as architects, landscapers, mechanical and electrical consultants and building contractors had to involve significant environmental considerations to satisfy Government regulatory requirements. For example, proposed buildings have to be suitable for the environment on the island, appropriate in building terms and positioned to enhance the natural features of the island. An integrated and cohesive approach adopted by the development team assembled in response to the challenges of the comprehensive submission needed to secure the winning development bid achieved these requirements.

\section{Traditional respect}

Despite the island being uninhabited and having no existing structures a unique mixture of local traditions has influenced the resorts development planning and design concepts and actual construction management (and the benefits in responding to them). Whilst contemporary in nature, the resorts planning and design philosophy respects local island architectural character and practices interpreted by an acclaimed Singapore-based architect, Chan Soo Khian. Architectural blueprints guided impact studies prior to implementation. In complementing the spirit of environmental stewardship, the design promotes rainwater harvesting and minimizes disruption to corals around the island. The concepts preserve and reinforce the existing foliage of the island. Waste treatment plants ensure minimal island pollution. 
These overviews and reflections are supported by an array of 'sustainability' driven responses such as assessed community needs and equitable economic commitments to the vision of seeking process based ecological performance outcomes that make the resort a leading example of small island development. The findings of the assessment reflect the structure of the tool and indicate the extensive range of inputs needed to achieve a sustainable development.

\section{Post Operational Evaluation (POE)}

As noted the standard is primarily a planning, design and construction focused tool however it recognises that decisions taken at the early stages of the development process will have profound impacts on the operational performance outcomes of a project. Other models or tools also concentrate on this phase but do not appear to continue monitoring total life cycle outcomes. This is a limited and inadequate analysis of the total development process and property investment. It can be stated that there is also a research concentration on early planning and design decisions. This work often takes little regard of the post occupancy phase of a program reflecting the continuing fragmentation of project delivery by the Industry [8]. These are important observations if for example government targets regarding carbon reduction are to be achieved. To reach such targets the necessary emission diminution will have to come from buildings such as the case study resort in the initial phases. Also the outcomes will need to be maintained and possibly improved through genuine ongoing performance results over considerable periods of time rather than non-achieved predictive wish listing at the design stage.

A major post construction feature of the Case Study is the commitment to Post Operation Evaluation (POE). When linked to the increasingly important area of Facilities Management [45] this long established systematic and rigorous process [46] provides a focus on building occupants and needs and equipment and systems performance. Results for 2009 [47] at the resort indicate that in key performance areas best practice is being exceeded by considerable margins. For example ratings for potable water consumption are $82 \%$, recycling $90 \%$ and cleaning products $16 \%$ better than industry best practice. These encouraging results demonstrate the efficacy of adopting a process based model if the goal is to delivery long term sustainable development gains.

\section{Findings, key lessons and conclusions}

This case study and others show how some developers are responding to the demand for the sustainable development and construction of tourism infrastructure. This case study also supports the growing recognition that projects need measuring in terms of their impacts and eventual performance. Of importance is that all parties to the processes involved recognize and acknowledge that only with the resulting data will critical decisions regarding sustainability have any certainty of success. Concurrently, when challenging 'business as usual' process norms this entails broad ecological agendas that 
require considerable inputs and in specific locations the implementation of innovative delivery strategies. This particular small island case study also confirms the critical need for on-going involvement between initial development progressions and associated long-term operational management practices adopted by project and facility managers.

Specifically developed sustainability and ecological performance documents for the resort's planning and design ensured compliance throughout the development in terms of delivery and quality. The enshrining of the documents and the commitment of a dedicated consultant aided users and maintained an important link between the developer, consultants, the building team, purchasers and other stakeholders. These actions and others that are noted suggest that for those who wish to undertake innovative, responsible and committed approaches on their developments they need at least to recognize the merits of an open mind in their approaches in seeking and achieving sustainable outcomes.

Discussions with the developer confirmed the high priority given to continuing performance assessment. Post Operation Evaluation now takes place on a yearly basis using a further tool created specifically for travel and tourism developments. This is a result of recognizing that many sustainable inputs and ensuing impacts take place over time and may come about by adjustment to aspects of the development a phenomenon likely seen in the critical social, cultural and economic areas.

Two key lessons from this particular assessment were firstly that the resort benefited from the integration of an 'Ecological Vision', which reflected environmental, cultural and economic sustainability. The resultant briefs, goals, aims and objectives aligned with the Building Planning and Design Standard's (BPDS) principles providing an opportunity to undertake an international recognized independent third party benchmarking and certification assessment.

Secondly, considerable effort can be required to overcome problems in sourcing the supply chain with regard to green systems and equipment. The location of remote communities requires companies that can properly service these projects with allowances made when assessing this aspect of development in developing tourism markets.

Accordingly, the Developer has responded to the demand for tourism infrastructure delivery managed in a sustainable manner and a measured development in terms of impacts and eventual ecological performance. The resultant information and data is critical for planning, design and management, decisions seeking an assurance of successful outcomes. By challenging the norms of resort delivery and opening their planning and design to the scrutiny of an internationally recognized building planning and design standard indicated a willingness to reduce if not mitigate entirely the impacts of development. The Developer challenged business as usual processes whilst recognizing that sustainable agendas require considerable inputs. The project achieved a high rating assessment due in part to the measurable implementation of an innovative delivery strategy and by a long-term commitment to the resort. This has confirmed other assessment findings regarding the need for on-going involvement with a development and the associated management processes. 
This willingness to put forward a sustainable agenda of their making has sought to recognize the relationships with clients, regulators and other stakeholders. The agenda used and approach taken has resulted in a more effective and sustainable development process resulting in a sustainable response to the growing leisure/active tourism based on islands and in developing coastal regions.

\section{References}

[1] World Tourism Organisation (WTO), 2011: 2010 International Tourism Results and Prospects for 2011, www.unwto.org (accessed January 2011).

[2] TIES, 2006; Global Ecotourism Fact Sheet (Research by Canopy Development). The International Ecotourism Society, Washington USA www.ecotourism.org (Accessed May 2009).

[3] Williams S, 2009: $2^{\text {nd }}$ Edition Tourism Geography, Routledge London UK.

[4] National Geographic, 2005: (Tourtellot J, Director of Sustainability) Sustainable Tourism Resource Centre, www.nationalgeographic.com (Accessed January 2009).

[5] French C, Craig-Smith S and Collier A, 2000: $2^{\text {nd }}$ Edition Principles of Tourism, Longman NSW Australia.

[6] Spenceley A, 2010: Responsible Tourism, Critical Issues for Conservation and Development Earthscan London UK.

[7] Swarbrooke J, 2005: Sustainable Tourism Management, CABI Publishing Oxen UK.

[8] Moore R, 2010: A Framework for Sustainable Development, Paper presented to the 16th Annual International Sustainable Development Research Conference May/June 2010 Kadoorie Institute The University of Hong Kong.

[9] Dodds S and Kelman I, 2008: How Climate Change is Conceived in Sustainable Tourism Policy, A Case Study of the Mediterranean Islands of Malta and Mallorca, Tourism Review International Vol. 12 pp. 57-70 www.cognizantcommunication.com (accessed January 2011).

[10] Grazer L and Marin C, 1999: Tourism and Sustainable DevelopmentFrom Theory to Practice, The Island Experience, Consejeria de Tourismo y Transportes Gobierno de Canerias.

[11] McElroy J, 2002: Managing Sustainable Tourism in the Small Island Caribbean the Journal of Ecological Economics, September 2000.

[12] Twining-Ward, L and Butler, R 2002:Implementing STD on a small island: Development and use of sustainable tourism development indicators in Samoa. Journal of Sustainable Tourism, 10 (5). pp. 363-387. ISSN 09669582.

[13] Gough K, Bayliss-Smith T, Connell J and Mertz O, 2010:Small island sustainability in the Pacific: Introduction to the special issue, Singapore Journal of Tropical GeographyVolume 31, Issue 1, Article first published online: 29 March 2010 Wiley (onlinelibrary.wiley.com accessed August 2011). 
[14] Nath S, Roberts J and Madhoo Y, 2010: Saving Small Island Developing States, Environmental and Natural Resource Challenges, Commonwealth Secretariat London UK.

[15] Mowforth M and Munt I, 2006: Tourism and Sustainability - Development and New Tourism in the Third World, Routledge London UK.

[16] Moore R, Kavanagh L, Hyde R, 2006: Using Case Studies to Evaluate the Effectiveness of an Environmental Assessment Tool for the Planning and Design of Precincts, - Paper presented to Subtropical Cities Conference Brisbane QLD Australia.

[17] Marmon A (Reference to the President of the Maldives), 2008: Reflections on World Tourism Day - Theme of Tourism responding to the Challenges of Climate Change, www.maldivestourismupdate.com (Accessed November 2009).

[18] McCarthy J, 2001: Climate Change 2001: Impacts, Adaptation, and Vulnerability, Cambridge University Press UK.

[19] Picard D and Robinson M, 2006: Festivals, Tourism and Social Change: Remaking Worlds,(Tourism and Cultural Change) Channel View Publications Clevedon UK.

[20] Telfer D and Sharpley R, 2008: Tourism and Development in the Developing World, Routledge Perspectives on Development, Routledge London UK.

[21] Dodds R, 2007: Malta's Tourism Policy - Standing Still or Advancing Toward Sustainability, Island Studies Journal Vol. 2 No.1 2007 pp. 47-66 Institute of Island Studies University of Prince Edward Island Canada.

[22] Moore R, 2006: Another Tool - Paper presented to ANZAScA Conference Wellington New Zealand.

[23] Huffadine M, 1999: Resort Design - Planning, Architecture and Interiors, McGraw-Hill London UK.

[24] WTO, 1999: Guide for Local Authorities on Developing Sustainable Tourism - Supplementary Volume on Asia and The Pacific, A Tourism and Environment Publication World Tourism Organisation Madrid Spain.

[25] Baker S, 2006: Sustainable Development, Routledge London UK.

[26] Birkeland J, 2008: Positive Development, From Vicious Circles to Virtuous Cycles - Through Built Environment Design, Earthscan London UK.

[27] Thompson P, 2010: What Sustainability is (and what it isn't), $2^{\text {ND }}$ Edition Chapter 1 Pragmatic Sustainability, Theoretical and Practical Tools. Editor [4].

[28] Bell S and Morse S, 2008: Sustainability Indicators - Measuring the Immeasurable, Earthscan London UK.

[29] Hyde R, Moore R, Kavanagh L Watt M, Prasad D, Blair J, 2007: Steering Sustainability - Indicators, audits and measuring success, RMIT NSW Australia Chapter 11.

[30] Williams A, 2008: The Enemies of Progress, The Dangers of Sustainability, Societas - Imprint Acadamy VA USA. 
[31] Moore R, 2010: Integration of an 'Ecological Vision' on a small coral island, Paper for Sustainable Tourism - Issues, Debates and Challenges Conference April 2010 Crete and Santorini Greece.

[32] Baud-Bovy M and Lawson F, 1998: Tourism and Recreation, Handbook of Planning and Design, Architectural Press Oxford UK.

[33] Sweeting J and Sweeting A, 2003: A Practical Guide to Good Practice in Managing Environmental and Social Issues in the Accommodation Sector, Centre for Environmental Leadership in Business, www.celb.org (Accessed May 2008).

[34] Sheldon P, 2005: The Challenges to Sustainability in Island Tourism, Occasional Paper 2005-01 0ctober TIM Hawaii USA.

[35] Moore R. Ed., Hyde R, Kavanagh L, Schiantez K, Prasad D, Blair J, Watt M, Bayada B and Hair A, 2009: The Case Studies - Using a Planning and Design Standard on Neighbourhoods and Precincts, STCRC Griffiths University Queensland Australia.

[36] Rey-Valette H, Laloe F and Le Fur J, 2007: Introduction to the issue concerning the use of sustainable development indicators, International Journal Sustainable Development Vol. 10 Nos1-2 2007.

[37] Moore S, 2010, Pragmatic Sustainability, Theoretical and Practical Tools, Routledge London UK.

[38] Hyde R, Moore R, Kavanagh L Watt M, Prasad D, Blair J, 2007: Steering Sustainability - Indicators, audits and measuring success, RMIT NSW Australia Chapter 11.

[39] Yin R, 2003: Case Study Research - Design and Methods, (4th Edition) Applied Social Research Method Series Vol.5 Sage Publications California USA.

[40] Kathan C, 2008: The Design of the Study and Case Selection. The University of Groningen, Netherlands. http://dissertations.ub.rug.nl (Accessed April 2008).

[41] Moore R, 2008: Alila Villas Hadadaa Maldives, Case Study Report for EC3 Global Green Globe Brisbane QLD Australia, www.earthcheck.org

[42] Moore R Ed. 2008: Green Globe Building Planning and Design Standard, EC3 Global (Earthcheck), www.earthcheck.org

[43] Gardiner P, 2005: Project Management - A Strategic Planning Approach, Palgrave MacMillan London UK.

[44] Stasinopoulos P, Smith M, Hargroves K and Desha C, 2009: Whole Systems Design - An Integrated Approach to Sustainable Engineering, Earthscan London UK.

[45] Park A, 1998: $2^{\text {nd }}$ Edition Facilities Management - An Explanation, Palgrave London UK.

[46] Preiser W, Rabinowitz H and White E, 1988: Post-Occupancy Evaluation Van Nostrand Reinhold New York USA.

[47] EC3 Global, 2011: Alila Villas Hadahaa Maldives, EC3 Global (Earthcheck) Brisbane Australia (see www.ec3global.com). 